\section{The American Association for Thoracic Surgery}

\section{Registration and Housing Now Open for AATS Week 2015}

AATS Week 2015 includes two terrific events: The Mitral Conclave (April 23-24, 2015, New York City) and AATS 95th Annual Meeting (April 25-29, 2015, Seattle, WA).

Register for both and receive a $\$ 100$ discount off the Mitral Conclave fee!

Registration and housing reservations are now open. Information can be found at http://aats.org/aatsweek/.

\section{Three ways to register:}

- Online at www.aats.org. Registration and hotel reservations can be made at the same time.

- Call the AATS/Experient Customer Service Desk

○ US: (800) 424-5249

○ International: (847) 996-5829

\section{- Mail/fax}

- Registration form is available upon request from meetings@aats.org. Once filled out it can be:

Mailed to AATS/Experient, P.O. Box 4088, Frederick, MD 21705, with check and credit card information or

Faxed to 301-694-5124 (fax requires credit card information)

\section{AATS MITRAL CONCLAVE 2015}

The AATS MITRAL CONCLAVE 2015 will bring the world's leading figures in mitral valve disease together for two days to discuss the latest information regarding management guidelines, imaging, pathology, minimally invasive approaches, percutaneous approaches, surgical techniques, devices, and long-term results. Faculty presentations of the latest available data, techniques, and state-of-the-art reviews will be supplemented by abstract and video presentations selected by the program committee from submitted original work. Selected manuscripts from accepted presentations will be considered for publication in a supplement to The Journal of Thoracic and Cardiovascular Surgery.

Program Director:

David H. Adams

Program Committee:

Anelechi C. Anyanwu

Tirone E. David

Pedro J. del Nido

Gilles D. Dreyfus

Volkmar Falk

Rakesh M. Suri

Hugo K.I. Vanermen

Francis C. Wells
For more details and to register for the Mitral Conclave, visit www.aats.org/mitral.

\section{CHECK OUT THESE AATS ANNUAL MEETING OPPORTUNITIES:}

Registration Opportunities for Residents/Fellows \& Medical Students

In support of the AATS's education mission, registration (Monday, April 27, to Wednesday, April 29) for residents/ fellows and medical students will be free during pre-registration.

Deadline for free registration: March 18, 2015

Starting March 19, 2015, the registration free will be $\$ 100$.

- Residents/fellows and medical students are invited to attend the Cardiothoracic Residents' Luncheon, Tuesday, April 28, at 12:30 PM. Lunch is complimentary but pre-registration is required.

- Residents/fellows and medical students also can preregister for the Saturday courses and Sunday symposia at no charge prior to March 18, 2015, after which each course/symposium will have a $\$ 100$ fee.

\section{Allied Health Package}

A discount is available to the Saturday courses and Sunday symposia for allied health professionals who pre-register.

The discount fee for both is only $\$ 350$.

Discount deadline: March 18, 2015

Starting March 19, 2015, the fee will be $\$ 450$.

\section{Saturday and Sunday Courses and Symposia}

Registration for a Saturday course and/or Sunday symposium will include access to all other course/symposia that are taking place that day.

Once a primary course is selected, the registrant will receive a syllabus book. Additional syllabi can be purchased onsite for $\$ 25 /$ each.

\section{AATS Grant Writing Workshop}

March 27, 2015, Bethesda, MD

Organized by the AATS Scientific Affairs and Government Relations Committee, the 2015 AATS Grant Writing Workshop will take place on Friday, March 27, 2015, at the Doubletree Bethesda in Bethesda, MD (9 miles from Washington, DC). This full-day program is designed for all levels of academic cardiothoracic surgeons interested in applying for grants.

The workshop will provide attendees with a better understanding of the complex nature of preparing and submitting grant proposals along with the techniques required to ensure submissions are of the highest quality. Through a didactic session, interactive panel discussions and a mock study 